\title{
The effect of Parkinson's disease on the ability to maintain a mental set
}

\author{
KA FLOWERS, C ROBERTSON \\ From the Department of Psychology, University of Hull, Hull, UK
}

SUMMARY In two experiments with an Odd-Man-Out choice discrimination task, Parkinsonian subjects had difficulty in alternating betwen two rules on successive trials. The pattern of errors suggested that the difficulty arises from an instability of cognitive set rather than any loss of reasoning ability, perseveration or increased distractibilty.

Mental changes are often reported in Parkinson's disease as an adjunct of the motor symptoms. Many investigators attribute these to dementia, from clinical observation ${ }^{2}$ or standardised IQ scores, ${ }^{34}$ or from reports of specific impairments in conceptual ability.$^{5-10}$ The idea that Parkinsonism gives rise to, or is associated with, dementia" also has some support from clinical, ${ }^{12}$ anatomical ${ }^{13}$ and biochemical ${ }^{14}$ studies linking the two. Some investigators, however, have found little deficit in Parkinsonian cognition, or losses restricted to one or two areas on$1 y,{ }^{15-21}$ so that the relationship of mental changes to the motor disorders or to the clinical state of the patient is often unclear.

An alternative interpretation of Parkinsonian difficulties has suggested that patients show certain specific behavioural changes rather than intellectual losses. On this view, efficient reasoning or memory function require not only adequate information processing capacity but also certain behavioural control mechanisms, such as sustained levels of arousal and motivation, and control of selective attention to relevant task demands. Disturbances of the latter may impair test performance even though a subject's thought processes are still intact (in which case scores may be significantly improved if, for example, rewards are used to increase motivation.) Some investigations have attributed Parkinsonian deficits to such behavioural disturbances. Poor learning or perceptual judgement, for example, have been ascribed to loss of arousal or attention, ${ }^{22}{ }^{23}$ to perseveration and inflexibility in acquiring concepts, ${ }^{24-26}$

Address for reprint requests: Dr KA Flowers, Dept of Psychology, University of Hull, Hull HU6 7RX, UK.

Received 3 April 1984 and in revised form 31 July 1984. Accepted 6 August 1984 or to an inability to maintain one mode of response against a competing alternative mode. ${ }^{27}$ Similar effects have been reported in animals with caudate lesions on a range of tasks, including discrimination-learning, problem-solving, alternation and bar-pressing. ${ }^{28-32}$

Deficits or this kind which are not intellectual, but consist rather of an impairment in the control of the subjects' responses, are typical of frontal lobe damage..$^{33-35}$ In view of the close connections of the striatum with the frontal cortex, ${ }^{36}{ }^{37}$ it is not surprising that some animal studies have found similar behavioural effects from caudate as from frontal lesions, ${ }^{30-32}$ while in man Bowen, ${ }^{27}$ Flowers $^{38}$ and Lees and $\mathrm{Smith}^{26}$ have suggested that Parkinsonian humans show frontal symptoms on various tasks. Alternatively the condition may represent a form of sub-cortical dementia. ${ }^{34}$

One kind of behavioural disturbance affecting cognitive function in Parkinson's disease is commonly described as a failure of mental "set". $2425273140-42$ Set may be defined as a state of brain activity which predisposes a subject to respond in one way when several alternatives are available. Control of set involves both maintaining one predisposition or "strategy" against other competing possibilities (that is, the motor equivalent of attention), and also changing the strategy when circumstances change. Both aspects are said to be disrupted with frontal cortical lesions in $\operatorname{man}^{3334}$ and animals ${ }^{4344}$ (different authors emphasising one or other disturbance.) Both, too, have been implicated in basal ganglia lesions in humans $202124-2640$ and animals. ${ }^{314142}$ The method we employed here was designed to test for the control of set in a reasoning task, our intention being to distinguish between cognitive impairment (in the understanding of con- 
cepts) on the one hand, and behavioural disturbances (in the control of applying concepts) on the other, in Parkinsonian patients.

For this experiment we devised a new concept/ reasoning task called the Odd-Man-Out test (OMO) derived from animal learning-set studies. ${ }^{3545}$ In the OMO test subjects are required to indicate which of a set of letters or numbers is different from the others on two series of cards, using two rules of classification alternately on successive trials. The number of correct choices on each trial, and the kind of errors made, indicate the ability of subjects (a) to apply a concept consistently, and (b) to alternate between one response set and another.

Previous studies of concept formation have used the Wisconsin Card Sorting Test (WCST), ${ }^{27}$ but there are a number of contraindications for its use in Parkinsonism. Firstly, its originators ${ }^{46}$ noted that normal elderly subjects nearly all failed to progress beyond the first category of sorting in the WCST, and showed perseveration. As our patients were all middle-aged to elderly, it was doubtful whether we could impute any impairments of this kind specifically to Parkinson's disease with the WCST. Secondly, pilot studies suggested to us that our subjects, far from failing to form concepts or to test them reasonably, often adopted elaborate categorisation hypotheses which were difficult to disprove with the WCST procedure, even in its clearer revised version. ${ }^{47}$ Interpretation of their failure to perform correctly, therefore, was problematical. Thirdly, there was no indication on the WCST procedure as to how quickly subjects learnt the initial concept, nor how many errors were made during that initial learning. Bowen ${ }^{27}{ }^{40}$ mentioned in passing that some Parkinsonian subjects failed to learn the first rule at all. These objections were found not to apply to the OMO test.

\section{Experiment 1}

\section{Method}

Subjects Parkinsonian subjects were from the neurological wards and outpatient clinics of Hull Royal Infirmary. Of 75 patients diagnosed as suffering from the disease, 11 had other disabling illnesses or handicaps as well, 11 could not be tested for practical reasons and four refused to co-operate. This left 49 patients, 28 men and 21 women. Their ages ranged from 37 to 83 years (mean 63.9, SD 9.2 years). One male patient had had a right-sided stereotaxic operation ten years previously, and one female patient had had operations eleven and fifteen years ago, on the left and right thalamus respectively. Every patient was rated independently by a doctor at 6-monthly intervals on the Webster scale of symptom severity and clinical disability ${ }^{48}$ OMO test scores, which were usually obtained in the week following an assessment, were correlated with the most recent Webster rating (range 5-20 in different patients from a total scale of $0-30$ ). Although most patients reported "good" and "bad" days and some within-day fluctuation in their symptoms subjectively, only one showed an overt on-off syndrome and there were only gradual changes in the Webster scores over the 6-month periods. As far as possible subjects were tested at the best time of a good day to obtain their optimum performance and to minimise the effects of any fluctuation in severity of the disease. Patients were also ranked in terms of duration of the disease, estimated from the date reported in the history when they noticed their first symptom. Duration ranged from 1 to 33 years.

Patients received one or more of the following groups of drugs: anti-cholinergics (15 patients); levodopa plus a dopa-decarboxylase inhibitor (Sinemet, Madopar: 31 patients); amantadine (10 patients); and bromocriptine (four patients). The drug regime was stable at the time of testing. Occasional patients were taking beta-blockers, antihistamines or tricyclic antidepressants, either for indications unrelated to Parkinson's disease, or as weak adjuvants for Parkinsonian symptoms.

The Control group was drawn from a pool of Parkinsonian patients' spouses, other patients with peripheral nerve lesions or spinal cord afflictions, and local volunteers. Fifty six subjects matched for age and background with the patient group were tested. There were 28 men and 28 women, whose ages ranged from $37-80$ (mean $65 \cdot 1$, SD 10.6 years). None of the controls had a history of nervous disease or serious head injury, and none was taking drugs which affect the central nervous system. Control and Parkinsonian groups were not matched directly for verbal IQ, but all of the patients scored at least 85 on an abbreviated Wechsler verbal scale (Vocabulary, Similarities, Digit Span, Arithmetic).

In order to assess the effect of age on performance on the OMO test, a third group of younger normal subjects was also tested. This group comprised 20 men and 20 women undergraduates at the University of Hull, all aged 20-30 years.

Within each group of subjects $t$ tests showed that there were no age differences between men and women, between those tested on Pack A or Pack B first, or between those presented with letters first or shapes first (see procedure below.) Within the Parkinsonian group there were no differences between any subgroup in average duration of the disease, the mean lying between 8-11 years in all cases. In this group also the average Webster rating at the time of testing was not different for men as against women, or Pack A subjects as against Pack B, but those presented with shapes first had slightly higher Webster ratings than those presented with letters first $(\bar{X}=11.4 \mathrm{cf} 9 \cdot 0 ; t=$ $2.319, \mathrm{p}<0.05)$.

Material Figure 1 shows the material used in Experiment 1 . Two packs of 16 cards were made up, in each of which there were eight sets of letters and eight sets of geometrical shapes. Shapes comprised large ( $35 \mathrm{~mm}$ high) and small (20 mm high) geometrical shapes drawn with black ink on white cards $120 \mathrm{~mm} \times 90 \mathrm{~mm}$ in size. Letters comprised upper case (16 mm high) and lower case (11 $\mathrm{mm}$ high) Letraset letters mounted in identical configurations. On each card two shapes or letters were the 


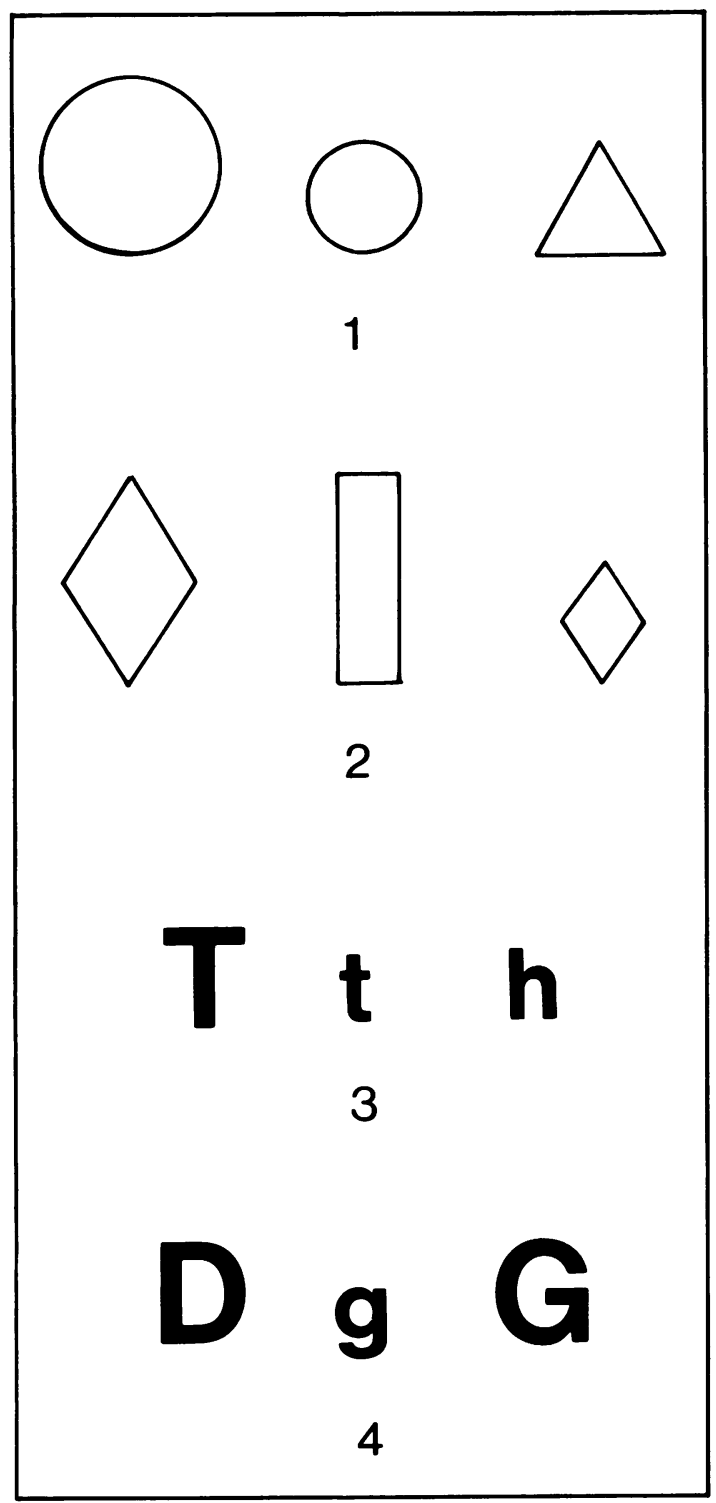

Fig 1 Odd-Man-Out Test: Experiment 1. Subjects have to indicate which of the three items on each card they think is different from the other two, using one of two possible rules. 1 \& 2: Shapes sets. Subjects choose either according to shape (triangle in 1, rectangle in 2) or according to size (large circle in 1, small diamond in 2). 3 \& 4: Letters sets. Subjects choose either according to letter ( $h$ in 3, $D$ in 4) or according to size ( $T$ in $3, g$ in 4). Subjects are free to choose either rule on the furst set, but must then apply it consistently throughout Trial 1; they must then apply the other rule on Trial 2, and alternate the two rules on later trials. same and the third different, and one of the two similar shapes/letters differed in size from the other two symbols (see fig 1). On half the cards in each pack the odd-man-out for size was a large item, and on half it was a small one. For the shape/letter comparison four pairs of shapes and letters were used, each item appearing once in its larger and once in its smaller form as the odd-man-out in one pack, and as the matched pair twice in the other pack. For each choice, therefore, subjects had to respond not to the items themselves, nor to the shapes/letters themselves, but to the overall relationship between the three symbols on the card. The position on the card of the odd-man-out for both shape and size varied from set to set, although they were not entirely evenly distributed between the three positions.

Half the subjects in each group were shown the eight letters cards first followed by the eight shapes cards for both packs, and half shown the shapes first and then the letters. Half the subjects were presented with Pack A first and half with Pack B first.

Procedure Control and Parkinsonian subjects were tested on the OMO test as part of a series of tests of motor and mental functions. Undergraduates were tested separately. Subjects sat at a desk facing the experimenter who held the first pack to be used in front of the subject. The standard instructions were: "On this card you can see three items. Two are the same and one is different. Can you tell me which one you think is the odd one out?" When the subject had indicated his first choice this was noted and the instructions continued. "Good. Now I want you to tell me which is the odd one out for all these sets of items as I show them to you, using the same rule you used for the first one. You have to apply the same rule each time. I will tell you whether you are right or wrong on each card. So, which is the odd one out for this set?..." The experimenter noted down each choice as it was made, including errors and second (and sometimes third) choices. After a correct response, the experimenter turned over the card to reveal the next set, occasionally making encouraging noises. If the choice was incorrect, the experimenter said "No, that's not right" and the subject had to choose again until he guessed correctly.

After the first pack had been run through (Trial 1) it was put face down on one side in view of the subject, and the second pack presented. The instructions then continued: "Now, here is another pack of cards with similar items on them. Again I want you to tell me for each set which item you think is the odd one out from the other two; but this time you must use a different rule to the one you used last time. Tell me the odd one out each time, using another rule." The cards in the second pack were dealt out in the same way as with the first Pack, and the subject's choices written down. Again a correction procedure was used. This constituted Trial 2.

When the second pack was finished it was in turn put face down in view on one side and the first pack picked up again. Subjects were then enjoined to indicate the odd one out for each card according to the first (original) rule and it was stressed that the task was the same as on Trial 1, with the same cards. Following this, the second pack was repeated, and the two packs then alternated once or twice more. Thus trials 3,5 , and 7 repeated the procedure and task of Trial 1 while trials 4,6 , and 8 repeated Trial 2 . 
After the last trial subjects were asked to say what they thought the rules used were. Some Parkinsonian patients who still seemed uncertain of the rules used were then told them explicitly, and asked to run through each pack again, to see if they could apply them once they were given directly (trials 9 and 10.)

On each trial the number of correct choices, and the kind of error made, were noted for each subject. Differences in score between groups and sub-groups, and for individuals between trials, were tested by the non-parametric Kruskal-Wallis analysis of variance, Mann-Whitney U-test, and Wilcoxon matched-pairs test (two-tailed), as the data are highly skewed in all groups and approach a ceiling effect on later trials for the control and undergraduate groups. Also variances in the Parkinsonian group were greater than those in the control group in all trials except the first. Correlations with age and clinical assessments were carried out with the non-parametric Spearman's rho test.

\section{Results}

(1) Choice of First Rule Subjects were free to choose either size or shape/letter as the first rule. In practice there was a bias according to whether letters or shapes were shown first, but this was the same in all groups. When letters were shown first, most subjects chose to classify by size, whilst when shapes were shown first, most classified by shape. The difference is significant on a $\chi^{2}$ test at the level of $p<0.01$ or better within every group; between groups there were no differences in the pattern of preferences.

(2) Accuracy of Choice An initial comparison of scores of subgroups within each of the three main groups of subjects showed that there was no difference on any trial between those who chose the minority first rule compared to those choosing the majority rule; nor between those shown Pack A first and those shown Pack B first. In all three groups subjects shown letters first performed slightly worse on all trials than those shown shapes first, but this parallel difference was small in all groups and only reached statistical significance for controls. As the same pattern of differences between Parkinsonian and control subjects was found for shapes-first and letters-first sub-groups analysed separately, results for subjects in the two sub-groups were combined for each main group.

There were thus 40 undergraduates, 56 controls and 49 Parkinsonian subjects overall, although these numbers were reduced on later trials as, for a variety of practical reasons, nine control and 17 Parkinsonian subjects were not tested on trials 7 and 8 , and only 26 Parkinsonians were tested on trials 9 and 10 after being told the two rules to apply. One patient missed trials 5 and 6 also.

The mean number of correct choices made by subjects in each group on Trials 1-8 are shown in table 1. Undergraduates have the highest scores in every trial and show an improvement in accuracy on both rules with repeated testing. Many subjects have reached a perfect performance by trials 7 and 8 , although the odd error is still being made. None of the scores for trials 2-6 are reliably different from those for Trial 1 (Wilcoxon $T$ scores all nonsignificant) but those for Trial 7 and 8 are just significantly better $(p<0.05)$. This group, therefore, starts off well and, if anything, improves with repetition; there is no sign of interference between the two rules in their performance.

Controls have virtually the same scores as undergraduates on Trial 1. They show a slight drop in accuracy on Trials 2 and 3 (both significant com-

Table 1 Number of correct choices in each Trial: Experiment 1

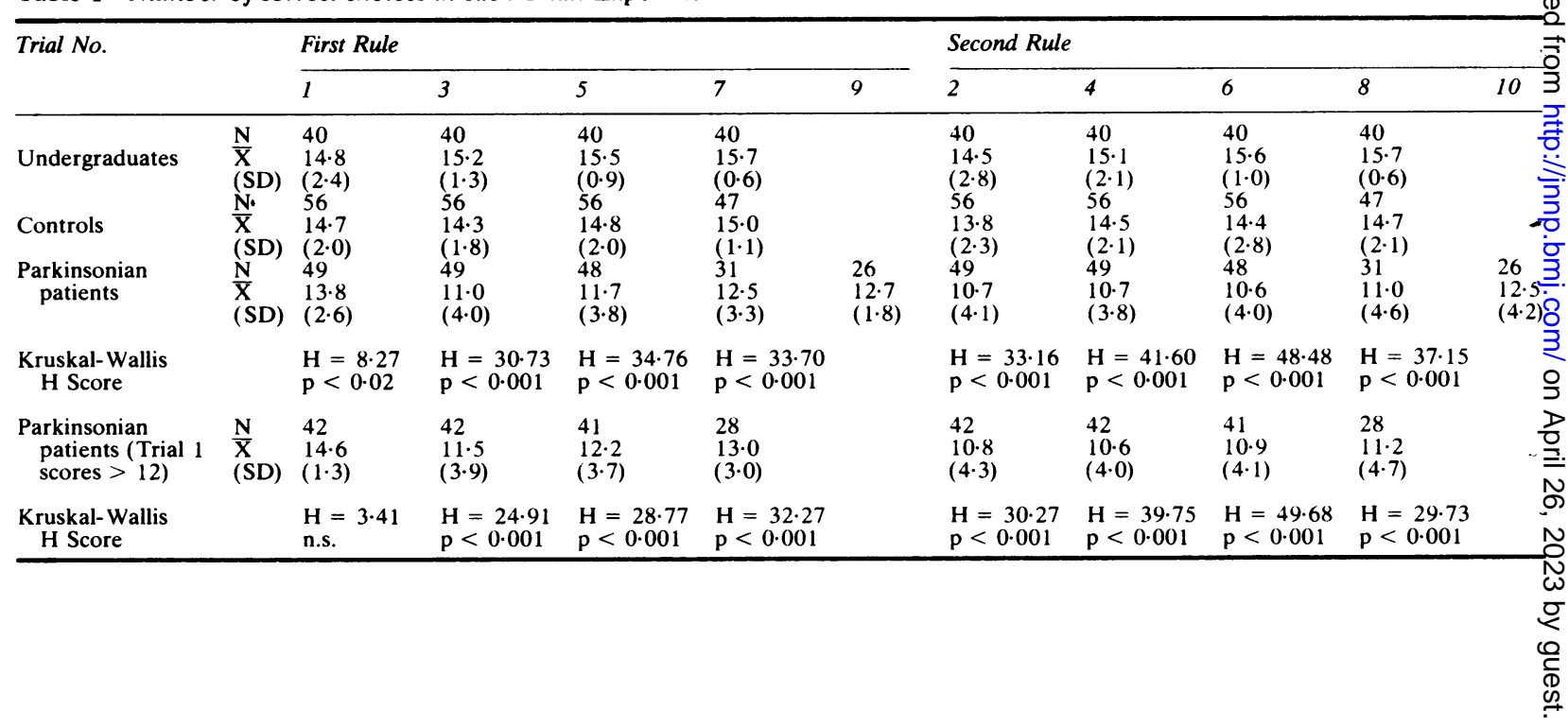


pared to Trial 1 scores; Wilcoxon $\mathrm{z}=2 \cdot 70, \mathrm{p}<0.01$ and $z=2 \cdot 16, p<0.05$ respectively), but then return to at least their level of performance on the first trial. This level is slightly below that of the undergraduates, but still averages about one error per trial only. This group, therefore, shows a slight initial interference when the second rule is introduced, but soon returns to the initial high level of classification, for both rules.

Parkinsonian subjects have an initial accuracy score slightly lower than that of the other two groups, the difference being statistically significant overall, and just reaching significance when patients are compared to controls and undergraduates separately. They still perform at a level which suggests a clear understanding of what they have to do, however, making just over two errors in 16 responses. On subsequent trials they show a markedly worse performance, both as compared with their own scores on Trial 1 (all Wilcoxon comparisons significant at the level of $p<0.001$ ), and as compared to control and undergraduate scores (all Kruskal-Wallis statistics significant at the level of $p$ $<0.001$-see table 1.) Unlike the other groups, the Parkinsonian group does not improve as the trials progress, but continues to produce more errors, especially on trials with the second rule.

Although the Parkinsonian score on Trial 1 is lower than that of the controls, only one subject made less than eight correct choices; that is, their performance is well above chance. When the seven subjects scoring less than 12 correct out of 16 on Trial 1 were excluded from the Parkinsonian group (so that the group's initial scores are equal to that of the controls) Parkinsonian scores for trials 2-8 are little changed and the same pattern of effects is still found (see table 1, lower lines.) The significant drop

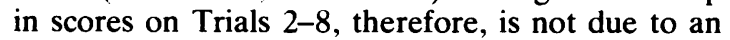

initial confusion in the Parkinsonian group being worse confounded on later trials.

On trials 9 and 10, Parkinsonian subjects show some improvement compared with their previous performance, but are still below the level of Trial 1 (Wilcoxon $\mathrm{z}=2.00, \mathrm{p}<0.05$ and $\mathrm{z}=1.65, \mathrm{p}<$ 0.10 respectively.) Thus even when the rules are explicitly known, discrimination performance is still beset with error in this group.

(3) Correlation with clinical features In the control group, OMO scores correlated with age for Trial 1 , Trial 2 and a "first-rule" score of trials $3+5$ combined, but not for a "second-rule" score of trials $4+6$ combined. This is perhaps surprising in view of the high scores of this group as a whole, but suggests that there may be an age effect in normals, and accords with the slightly lower scores for the controls on all trials as compared with undergraduates. In the Parkinsonian group, however, the correlation of OMO scores with age is not significant for Trial 1 and Trial 2, but it is for trials $3+5$ combined $\left(r_{s}=\right.$ $-0.309, t=2 \cdot 227, \mathrm{p}<0.05)$ and for trials $4+6$ combined $\left(r_{\mathrm{s}}=-0.447, t=3.426, \mathrm{p}<0.01\right)$. A similar relationship was found with Webster ratings in the Parkinsonian group, although age and Webster scores were not themselves correlated in this sample. Duration did not correlate significantly with scores on any trial.

The effect of symptom severity on OMO performance is clearer when scores are divided up according to Webster ratings. For this analysis the Parkinsonian group was divided into a Mild (Webster rating 5-8), Moderate (rating 9-12) and Severe (rating 13-20) subgroups. Scores for these three subgroups are shown in table 2, together with the KruskalWallis analysis of variance of differences in their scores. From this it can be seen that there is little difference between sub-groups on trials 1 and 2, but

Table 2 Parkinsonian accuracy scores according to severity of disease

\begin{tabular}{|c|c|c|c|c|c|c|c|c|c|}
\hline Trial No. & & 1 & 3 & 5 & 7 & 2 & 4 & 6 & 8 \\
\hline Controls & $\begin{array}{l}\frac{N}{X} \\
(S D)\end{array}$ & $\begin{array}{l}56 \\
14 \cdot 7 \\
(2 \cdot 0)\end{array}$ & $\begin{array}{l}56 \\
14 \cdot 3 \\
(1 \cdot 8)\end{array}$ & $\begin{array}{l}56 \\
14 \cdot 8 \\
(2 \cdot 0)\end{array}$ & $\begin{array}{l}47 \\
15 \cdot 0 \\
(1 \cdot 1)\end{array}$ & $\begin{array}{l}56 \\
13 \cdot 8 \\
(2 \cdot 3)\end{array}$ & $\begin{array}{l}56 \\
14 \cdot 5 \\
(2 \cdot 1)\end{array}$ & $\begin{array}{l}56 \\
14.4 \\
(2 \cdot 8)\end{array}$ & $\begin{array}{l}47 \\
14 \cdot 7 \\
(2 \cdot 1)\end{array}$ \\
\hline $\begin{array}{l}\text { Mild } \\
\text { 2Parks. } \\
\text { Gp. } \\
\text { Moderate } \\
\text { Parks. } \\
\text { Gp. } \\
\text { - Severe } \\
\text { Parks. } \\
\text { Sp. }\end{array}$ & $\begin{array}{l}\frac{N}{X} \\
(S D) \\
N \\
\bar{X} \\
(S D) \\
N \\
\bar{X} \\
(S D)\end{array}$ & $\begin{array}{l}17 \\
14 \cdot 3 \\
(2 \cdot 5) \\
18 \\
13 \cdot 5 \\
(2 \cdot 5) \\
14 \\
13 \cdot 5 \\
(2 \cdot 7)\end{array}$ & $\begin{array}{l}17 \\
13 \cdot 6 \\
(3 \cdot 2) \\
18 \\
10 \cdot 1 \\
(4 \cdot 2) \\
14 \\
9 \cdot 1 \\
(3 \cdot 2)\end{array}$ & $\begin{array}{l}17 \\
14.5 \\
(1.9) \\
18 \\
10.9 \\
(3.6) \\
13 \\
8.9 \\
(3.6)\end{array}$ & $\begin{array}{l}11 \\
14.9 \\
(1 \cdot 7) \\
13 \\
11.7 \\
(3 \cdot 1) \\
7 \\
10.3 \\
(3 \cdot 6)\end{array}$ & $\begin{array}{l}17 \\
11 \cdot 8 \\
(4 \cdot 5) \\
18 \\
9 \cdot 5 \\
(4 \cdot 0) \\
14 \\
10 \cdot 8 \\
(3 \cdot 5)\end{array}$ & $\begin{array}{l}17 \\
12 \cdot 2 \\
(4 \cdot 1) \\
18 \\
10 \cdot 1 \\
(4 \cdot 2) \\
14 \\
9 \cdot 5 \\
(2 \cdot 4)\end{array}$ & $\begin{array}{l}17 \\
12 \cdot 8 \\
(3 \cdot 9) \\
18 \\
8 \cdot 8 \\
(3 \cdot 8) \\
13 \\
10.2 \\
(3 \cdot 5)\end{array}$ & $\begin{array}{l}11 \\
14 \cdot 3 \\
(3 \cdot 5) \\
13 \\
9 \cdot 4 \\
(4 \cdot 5) \\
7 \\
8 \cdot 7 \\
(3 \cdot 7)\end{array}$ \\
\hline $\begin{array}{l}\text { Kruskal-Wallis } \\
\text {, H Score }\end{array}$ & & $\begin{array}{l}\mathrm{H}=1.51 \\
\mathrm{~ns}\end{array}$ & $\begin{array}{l}\mathrm{H}=12.26 \\
\mathrm{p}<0.01\end{array}$ & $\begin{array}{l}H=17.94 \\
p<0.001\end{array}$ & $\begin{array}{l}\mathrm{H}=12.55 \\
\mathrm{p}<0.01\end{array}$ & $\begin{array}{l}\mathrm{H}=4 \cdot 10 \\
\mathrm{~ns}\end{array}$ & $\begin{array}{l}\mathrm{H}=4.84 \\
\mathrm{~ns} \\
(\mathrm{p}<0.10)\end{array}$ & $\begin{array}{l}H=9.88 \\
p<0.01\end{array}$ & $\begin{array}{l}H=28.76 \\
p<0.001\end{array}$ \\
\hline
\end{tabular}


marked differences on later trials. Thus all subjects are close to the control level on the first classification, and all show a marked drop on Trial 2. But whereas the Mild sub-group recover and almost match the controls on later trials, the Moderate and Severe sub-groups show continuing difficulty, especially on trials with the second rule. These results reinforce the idea that the effect of Parkinsonism is on the ability to alternate between two rules rather than on the capacity to formulate and apply a concept initially.

Correlations with the Webster ratings for tremor, rigidity and bradykinesia separately were also all negative, but were not large enough to reach significance, probably because, with only three rating levels, the scale does not discriminate between subjects sufficiently on single symptoms alone.

Verbal IQ scores for the Parkinsonian subjects did not correlate with OMO scores for Trial 1 , but did so for Trial $2\left(r_{s}=0.442\right)$, Trials $3+5\left(r_{s}=\right.$ $0.441)$ and Trials $4+6\left(r_{s}=0.454\right)$, all at the level $p<0.02$. This is the same pattern of correlation as with the Webster scores-which also correlate with verbal IQ significantly $\left(r_{s}=0.497, p<0.01\right)$. Thus neither their clinical disability nor their verbal IQ level determine the patients' initial performance on the OMO test, but the more severe their Parkinsonism is, the lower their verbal IQ and subsequent OMO scores are likely to be. Subjects' verbal IQ levels do not, therefore, determine performance on the OMO test, but show a parallel decline with the progression of the disease.

(4) Errors Errors made in trials 3 and 5 were combined to give a "first-rule" error score, and those made in trials 4 and 6 combined to give a "second-rule" error score in the control and Parkinsonian groups. When errors were plotted against the 16 positions in the card sequence, both control scores showed a preponderance of errors early on, indicating that these subjects tended to make their errors at the start of each trial rather than later. This trend was significant $\left(\chi^{2}\right.$ scores significant at the level of $p<0.001)$. Parkinsonian errors, in contrast, occurred in all parts of the sequence $\left(\chi^{2}\right.$ scores both NS) implying that these subjects made errors evenly throughout the trials. Inspection of the protocols suggested that errors were not repeated from trial to trial for the same cards, but occurred in a fairly haphazard fashion throughout the series. Often errors were made on later trials for items that had been correctly identified in earlier ones. The pattern of errors did not, therefore, suggest perseveration by Parkinsonian subjects, but a more erratic fluctuation, whereby they occasionally misapplied the rules as they continued through the series of responses.

With three items per set, only two errors were possible: choosing the alternative odd-man-out or choosing the common item. Table 3 shows the number of errors of each kind for 41 control and 38 Parkinsonian subjects whose errors were distinguished in the records this way. In both groups most errors fell in the "alternative OMO" category; this is true for errors on trials 1 and 2 also. Overall only four out of 41 control subjects and four out of 38 Parkinsonian subjects made more common-item choices than alternative OMO choices (and these subjects account for almost half the common-item errors.) Thus, although many subjects were inaccurate on these trials, their errors were not mere guesses and only one or two could be regarded as confused, that is, choosing at random.

\section{Discussion}

From the results of Trial 1 it seems that Parkinsonian patients are well able to understand and apply a concept in this choice discrimination task, even though their scores are overall slightly lower than those of the controls. But a marked difficulty becomes apparent when the second rule is introduced. Then they start to make errors in classification, mostly by reverting to the alternative rule. Although their scores are still well above chance, Parkinsonian patients are more subject to occasional lapses in maintaining a given "set". This applies to later trials with the first rule as well as to those with the second rule, so the effect is not simply perseveration on the first concept. Parkinsonian patients seem less able to maintain one of the possible mental "sets" against the other when both

Table 3 Number of errors in each category: Experiment 1

\begin{tabular}{|c|c|c|c|c|}
\hline & \multicolumn{2}{|l|}{ Controls } & \multicolumn{2}{|c|}{ Parkinsonians } \\
\hline & Alt. $O M O$ & Common Item & Alt. $O M O$ & Common Item \\
\hline $\begin{array}{l}\text { Trials } 3+5 \\
\text { Trials } 4+6\end{array}$ & $\begin{array}{l}95 \\
85\end{array}$ & $\begin{array}{r}13 \\
9\end{array}$ & $\begin{array}{l}311 \\
308\end{array}$ & $\begin{array}{r}71 \\
100\end{array}$ \\
\hline $\begin{array}{l}\text { Total Errors } \\
(\%)\end{array}$ & $\begin{array}{l}180 \\
(89 \cdot 1)\end{array}$ & $\begin{array}{l}22 \\
(10 \cdot 9)\end{array}$ & $\begin{array}{l}618 \\
(78 \cdot 3)\end{array}$ & $\begin{array}{l}171 \\
(21 \cdot 7)\end{array}$ \\
\hline
\end{tabular}


have been brought to their attention, with the result that they tend to oscillate between the two.

Although this tendency is found to a small degree in the control group of elderly normal subjects on trials 2 and 3 , they improve on later trials. Anecdotal observation of these subjects, and of many undergraduates, suggested that they, too, quite often found themselves about to make the typical Parkinsonian error, but checked themselves before doing so. In other words, the tendency to "flip over" to the competing rule was present in normal subjects, but was spontaneously corrected before the response was made. A pilot experiment showed that undergraduates increased their error rate in this test when the rate of presentation of the cards was increased by urging subjects to respond as quickly as possible. This occurred presumably because subjects were then unable to "double check" their responses and correct them where a reversion of set had occurred. The tendency to oscillate set, therefore, is probably present in all subjects, but normals are able to suppress it to maintain a given criterion against the competition of alternatives. Parkinsonian subjects are less efficient at inhibiting this oscillation; their difficulty increases with the severity of the disease.

The results for Experiment 1 suggested that Parkinson's disease interferes with the ability to maintain one rule against a possible second one. With only three items per choice, however, it is unclear whether the lure of the the alternative item is due to intrusion by a competing set or to some form of distractibility to novelty (that is, subjects are drawn to the stimulus ignored last time.) A second experiment was therefore designed, in which a fourth item was introduced, offering a third possible way to categorise the stimuli. The intention was to see if the presence of an extra irrelevant stimulus affects discrimination performance, for example, by distracting attention or causing confusion.

Experiment 2 also gave us the chance to replicate the effect of Experiment 1 with a number of controls: (a) items were rotated systematically in position on the cards, to check for perseveration of errors on individual items or positions in the sequence; (b) letters and shapes were presented in separate tests on different occasions; and (c) every subject was tested for eight trials whatever level of accuracy they reached, and two trials were repeated after the rules had been explained explicitly, to see if practice and repeated testing on the OMO test helped (or possibly hindered) subjects.

\section{Experiment 2}

Method

Subjects Sixteen idiopathic Parkinsonian subjects were tested, 11 of whom had taken part in Experiment 1. There were nine men and seven women, whose ages ranged from 39-71 (mean 62.3, SD 8.3 years.) Duration of the disease ranged from under a year to sixteen years, with an average of 5.7 years. Webster ratings ranged from 3-16, with a mean of 9.9. The group thus covered a range of clinical severity, but with a predominance of moderately affected patients. Their drug regimes were stable at the time of testing. None had undergone thalamic operations. Verbal IQs on the abbreviated scale ranged from 83 to 124 .

Sixteen control subjects were tested, matched with the Parkinsonian group for age and background. They were all spouses or friends of the patients. There were six men and 10 women, whose ages ranged from $58-71$ (mean $64 \cdot 3$, SD 4.5).

Material For this experiment two sets of material were prepared, called Shapes and Letters, each comprising two packs of 12 cards (see figs 2 and 3.) On each card there were four symbols, drawn as before with one item differing in size from the others, one differing in shape or letter, and one differing in being drawn in outline (open) or solid black (filled) form. Within each of the four packs, the position of the odd-man-out for each category, and of the common item, was randomised so as to appear equally often in each position on the card. For the Letters series, three pairs of letters were used: $a-b, d-g$ and $h-t$. Each letter appeared once as an odd-man-out item with its letter pair in its large, small, open and filled form; the combinations were all divided equally between the two packs to give a balanced presentation. For the Shapes series, six shapes were used, each one appearing as the odd shape with all possible combinations of one other shape, and as the common shape in all possible combinations with a third one; these too were balanced throughout the two packs. Subjects tending to choose the same item, character, or position on the card, therefore, or to choose the third stimulus category on later trials, would make predictable mistakes in terms of the proportion of errors of different kinds throughout the sequence.

Procedure Each subject was tested on first Shapes and then Letters, on two separate occasions about a week apart. Half the subjects in each group were presented with Pack A first, and half with Pack B. The starting card was varied for each subject. The procedure was the same as in Experiment 1, with all subjects performing for eight trials at first, and then for two further trials after being asked what they thought the rules were, having the possibilities explained to them, and repeating them back to the experimenter.

\section{Results}

(1) Choice of first rule In both tests the number of subjects choosing each of the three possible rules on Trial 1 was fairly even, although shape was chosen more often on the Shapes test in both groups than the other two characteristics. The choice of second rule was also evenly spread between control and Parkinsonian groups in the distribution of choices. The choice of rules in both groups is thus more or less arbitrary. 


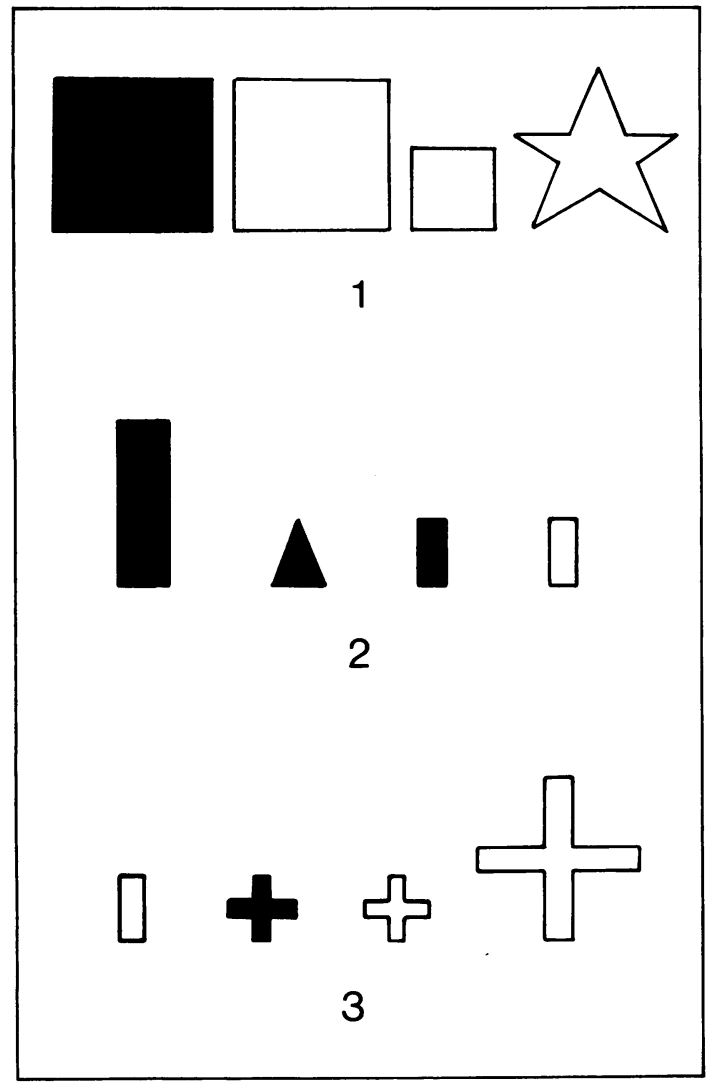

Fig 2 Odd-Man-Out Test: Experiment 2 (Shapes). Subjects have to indicate which item on each card they think is different from the other three, according to either (a) shape (star in 1, triangle in 2, rectangle in 3), or (b) size (small square in 1, large rectangle in 2, large cross in 3), or (c) open or filled form (black square in 1, open rectangle in 2, black cross in 3). As in Experiment 1, subjects may choose any of the three rules at furst (Trial 1) and then either of the two others (Trial 2); on later trials they must then alternate between the two chosen rules, ignoring the third option throughout.

(2) Accuracy of choice In neither group were there any notable differences between those presented with Pack A first and those shown Pack B first; nor between those choosing different rules; nor between those who had experienced the task before in Experiment 1 and those new to it. Accuracy scores for both tests are shown in table 4, together with their Mann-Whitney statistics. The results for both tests are very similar, and replicate those of Experiment 1. For both Shapes and Letters there is no reliable difference between the groups on Trial 1, and only one Parkinsonian subject in each test scores lower than eight correct, so all the initial

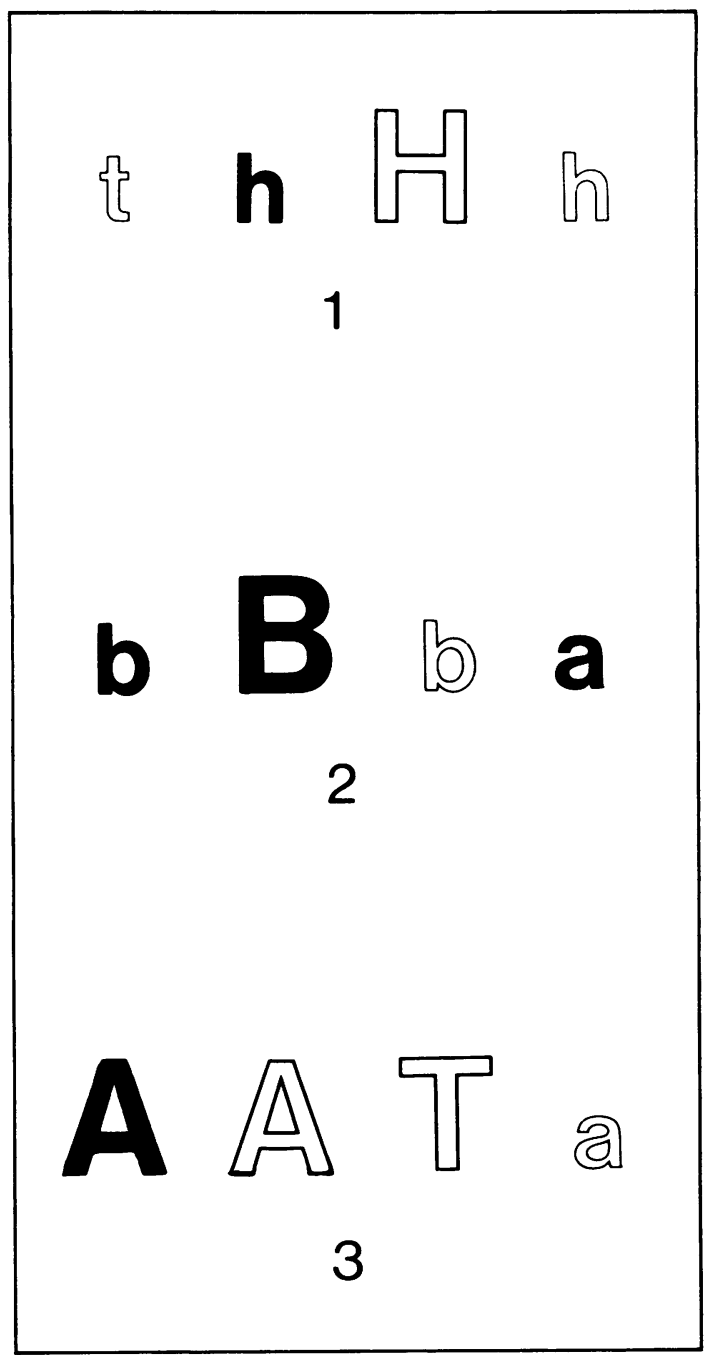

Fig 3 Odd-Man-Out Test: Experiment 2 (Letters).

Subjects choose according to either (a) letter $(t$ in $1, a$ in 2 , $T$ in 3$)$, or (b) size ( $H$ in 1, B in 2, $a$ in 3), or (c) open or filled form (black $h$ in 1, open $b$ in 2, black $A$ in 3). Test procedure as in Fig. 2.

scores are well above chance. But Parkinsonian subjects are worse than controls on Trials 2-8 at the level of $p<0.05$ or better.

Within the groups, Control scores show little change from trial to trial on either test, all scores staying above 11 out of 12 on average. In the Parkinsonian group, scores for Trials 2-8 are lower than those for Trial 1 in both tests, the difference being statistically significant for all trials in the Letters test and for Trials 3 and 5 in the Shapes test (Wilcoxon T 
The effect of Parkinson's disease on the ability to maintain a mental set

Table 4 Number of correct choices in each Trial: Experiment 2

\begin{tabular}{|c|c|c|c|c|c|c|c|c|c|c|c|}
\hline \multirow[t]{2}{*}{ Trial No. } & & \multicolumn{5}{|l|}{ First Rule } & \multicolumn{5}{|c|}{ Second Rule } \\
\hline & & $I$ & 3 & 5 & 7 & 9 & 2 & 4 & 6 & 8 & 10 \\
\hline \multirow{2}{*}{$\begin{array}{l}\text { Shapes Test } \\
\text { Control Group } \\
(\mathrm{N}=16) \\
\text { Parkinsonian } \\
\text { Group } \\
(\mathrm{N}=16)\end{array}$} & $\begin{array}{l}\bar{X} \\
(S D)\end{array}$ & $\begin{array}{l}11 \cdot 8 \\
(0 \cdot 4)\end{array}$ & $\begin{array}{l}11 \cdot 3 \\
(1 \cdot 3)\end{array}$ & $\begin{array}{l}11 \cdot 2 \\
(1 \cdot 3)\end{array}$ & $\begin{array}{l}11 \cdot 5 \\
(1 \cdot 0)\end{array}$ & $\begin{array}{l}11 \cdot 5 \\
(0.8)\end{array}$ & $\begin{array}{l}11.4 \\
(0.9)\end{array}$ & $\begin{array}{l}11 \cdot 2 \\
(2 \cdot 0)\end{array}$ & $\begin{array}{l}11 \cdot 1 \\
(1 \cdot 9)\end{array}$ & $\begin{array}{l}11 \cdot 5 \\
(1.5)\end{array}$ & $\begin{array}{l}11 \cdot 7 \\
(0 \cdot 7)\end{array}$ \\
\hline & $\begin{array}{l}\bar{X} \\
(\mathrm{SD})\end{array}$ & $\begin{array}{c}10 \cdot 4 \\
(2 \cdot 3)\end{array}$ & $\begin{array}{r}8 \cdot 5 \\
(2 \cdot 8)\end{array}$ & $\begin{array}{r}8 \cdot 4 \\
(3 \cdot 3)\end{array}$ & $\begin{array}{r}9 \cdot 1 \\
(2 \cdot 4)\end{array}$ & $\begin{array}{l}11 \cdot 5 \\
(1 \cdot 0)\end{array}$ & $\begin{array}{r}9 \cdot 8 \\
(2 \cdot 3)\end{array}$ & $\begin{array}{r}9 \cdot 3 \\
(3 \cdot 1)\end{array}$ & $\begin{array}{r}8 \cdot 7 \\
(3 \cdot 5)\end{array}$ & $\begin{array}{r}8 \cdot 8 \\
(2 \cdot 9)\end{array}$ & $\begin{array}{l}11 \cdot 1 \\
(1 \cdot 4)\end{array}$ \\
\hline $\begin{array}{l}\text { Mann-Whitney } \\
\text { U-test }\end{array}$ & & $\begin{array}{l}\mathrm{U} \\
\mathrm{ns}\end{array}$ & $\begin{array}{l}U=47 \\
p<0.01\end{array}$ & $\begin{array}{l}U=49 \\
p<0.01\end{array}$ & $\begin{array}{l}U=32 \\
p<0.001\end{array}$ & $\begin{array}{l}\mathrm{U}=97 \\
\mathrm{~ns}\end{array}$ & $\begin{array}{l}U=63 \\
p<0.05\end{array}$ & $\begin{array}{l}U=66 \\
p<0.05\end{array}$ & $\begin{array}{l}U=66 \\
p<0.05\end{array}$ & $\begin{array}{l}U=41 \\
\mathrm{P}<0.01\end{array}$ & $\begin{array}{l}\mathrm{U}=78 \\
\mathrm{~ns}\end{array}$ \\
\hline $\begin{array}{l}\text { Letters Test } \\
\text { Control Group } \\
(\mathrm{N}=16) \\
\text { Parkinsonian }\end{array}$ & $\begin{array}{l}\bar{X} \\
(\mathrm{SD})\end{array}$ & $\begin{array}{l}11 \cdot 5 \\
(1 \cdot 3)\end{array}$ & $\begin{array}{l}11 \cdot 2 \\
(2 \cdot 1)\end{array}$ & $\begin{array}{l}10 \cdot 9 \\
(2 \cdot 7)\end{array}$ & $\begin{array}{l}11 \cdot 0 \\
(1 \cdot 9)\end{array}$ & $\begin{array}{l}11 \cdot 9 \\
(0 \cdot 3)\end{array}$ & $\begin{array}{l}11 \cdot 3 \\
(1 \cdot 1)\end{array}$ & $\begin{array}{l}11 \cdot 1 \\
(1 \cdot 3)\end{array}$ & $\begin{array}{l}11 \cdot 1 \\
(1 \cdot 6)\end{array}$ & $\begin{array}{l}11 \cdot 2 \\
(1 \cdot 5)\end{array}$ & $\begin{array}{l}11 \cdot 6 \\
(0.9)\end{array}$ \\
\hline $\begin{array}{l}\text { Group } \\
(\mathrm{N}=16)\end{array}$ & $\begin{array}{l}\bar{X} \\
(\mathrm{SD})\end{array}$ & $\begin{array}{l}10 \cdot 8 \\
(2 \cdot 2)\end{array}$ & $\begin{array}{r}7 \cdot 8 \\
(3 \cdot 2)\end{array}$ & $\begin{array}{r}7 \cdot 8 \\
(3 \cdot 1)\end{array}$ & $\begin{array}{r}8.0 \\
(2 \cdot 9)\end{array}$ & $\begin{array}{l}10 \cdot 9 \\
(1 \cdot 3)\end{array}$ & $\begin{array}{c}8 \cdot 4 \\
(3 \cdot 1)\end{array}$ & $\begin{array}{r}8 \cdot 5 \\
(2 \cdot 7)\end{array}$ & $\begin{array}{r}7 \cdot 9 \\
(2 \cdot 6)\end{array}$ & $\begin{array}{r}8.4 \\
(2 \cdot 6)\end{array}$ & $\begin{array}{l}10.8 \\
(1.9)\end{array}$ \\
\hline $\begin{array}{l}\text { Mann-Whitney } \\
\text { U-test }\end{array}$ & & $\begin{array}{l}\mathrm{U}=97 \\
\mathrm{~ns}\end{array}$ & $\begin{array}{l}U=51 \\
\mathrm{p}<0.01\end{array}$ & $\begin{array}{l}U=58 \\
p<0.01\end{array}$ & $\begin{array}{l}U=51 \\
p<0.01\end{array}$ & $\begin{array}{l}\mathrm{U}=61 \\
\mathrm{p}<0.05\end{array}$ & $\begin{array}{l}U=51 \\
\mathrm{p}<0.01\end{array}$ & $\begin{array}{l}U=57 \\
p<0.01\end{array}$ & $\begin{array}{l}\mathrm{U}=39 \\
\mathrm{p}<0.001\end{array}$ & $\begin{array}{l}U=47 \\
p<0.01\end{array}$ & $\underset{\mathrm{nS}}{\mathrm{U}}=89$ \\
\hline
\end{tabular}

scores $\mathrm{p}<0.05$ or better); on the other trials the difference does not quite reach significance.

Scores on the (second) Letters test in the Parkinsonian group are slightly lower than equivalent scores in the (first) Shapes test for Trials 2-8, implying that the Parkinsonian deficit is not a matter of slow learning but persists even when subjects have performed the task before, including having the principle explained to them at the end.

On trials 9 and 10 the Parkinsonian performance improves almost to the level of Trial 1 on both tests, so that they are virtually the same as the Control scores. Making the rules explicit, therefore, seems to help these subjects in their choice discrimination, although the effect does not carry over to the second Letters test, where the impairment on Trials $2-8$ is slightly greater compared to that shown on the first test. The effect thus persists even when subjects have tackled the task before.

(3) Correlation with clinical features Scores for Trial 1 and 2 were correlated directly with age, duration and Webster rating in the Parkinsonian group.
Scores for later trials were combined into a "firstrule" score (trials 3,5 and 7 combined) and a "second-rule" score (trials 4, 6 and 8 combined). In the Control group, none of the accuracy scores correlated with age in either test. In the Parkinsonian group there was only one significant correlation with age: the second-rule score in the Letters test $(p<$ $0 \cdot 05)$. Duration of Parkinsonism did not correlate with any scores, and Webster ratings in only two cases: Shapes test second-rule scores $\left(r_{s}=-0.539\right.$, $\mathrm{p}<0.05)$ and Letters test first-rule scores $\left(\mathrm{r}_{\mathrm{s}}=\right.$ $-0.589, p<0.05)$. What correlations there were in these relatively small groups, therefore, were with the scores for later trials, not for Trial 1 or 2 . This repeats the effects found in Experiment 1, although to a lesser extent.

There were no significant correlations of Verbal IQ with OMO scores in either the Control or Parkinsonian group in Experiment 2 (despite the wide range of Verbal IQs in the patient group) again probably because of the small numbers involved.

(4) Errors Errors for trials 3,5 and 7 and for trials

Table 5 Numbers of errors in each category: Experiment 2

\begin{tabular}{|c|c|c|c|c|c|c|}
\hline & \multicolumn{3}{|l|}{ Controls } & \multicolumn{3}{|c|}{ Parkinsonians } \\
\hline & Alt. $O M O$ & Third Category & Common Item & Alt. $O M O$ & Third Category & Common Item \\
\hline \multicolumn{7}{|l|}{ Letters } \\
\hline Trials $3+5+7$ & 33 & 14 & 0 & 176 & 21 & 2 \\
\hline Trials $4+6+8$ & & 6 & 1 & 147 & 30 & \\
\hline $\begin{array}{l}\text { Total Errors } \\
(\%)\end{array}$ & 67 & 20 & 1 & 323 & 51 & 3 \\
\hline \multicolumn{7}{|l|}{ Shapes } \\
\hline Trials $3+5+7$ & 31 & 1 & 0 & 147 & 10 & 4 \\
\hline Trials $4+6+8$ & & 1 & 0 & 143 & 10 & 4 \\
\hline $\begin{array}{l}\text { Total Errors } \\
(\%)\end{array}$ & 65 & 2 & 0 & 290 & 20 & 8 \\
\hline & $(97.0)$ & $(3 \cdot 0)$ & (0) & $(91 \cdot 2)$ & $(6 \cdot 3)$ & $(2 \cdot 5)$ \\
\hline
\end{tabular}


4, 6 and 8 were combined for analysis by card, by position in the sequence, and by position on the cards. $\chi^{2}$ tests showed that errors were not concentrated on any particular card in the pack, nor on any particular position in the sequence of presentation except in one instance (Letters test second-rule errors, which were concentrated in the first half of the series, $\chi^{2}=26 \cdot 00, p<0 \cdot 01$ ). Only two subjects of the Parkinsonian group showed a significant unevenness in the occurrence of errors for the four positions on the cards, and for one of these the effect was to make markedly fewer errors in one place than the others, rather than to concentrate them on one place. There is thus little evidence of subjects showing perseveration bias for particular items on the cards, for particular points in the test series, or for any of the four symbol positions on the cards.

When subjects make errors in Experiment 2, they can choose either the alternative odd-man-out (that is, the one appropriate to the other rule of the two they are using) or the item for the third category, or the common item. The number of errors of each kind made in trials 1,2 , and first-rule and secondrule trials combined are shown for each test in Table 5 . Here the proportion of errors of each kind is about the same in control and patient groups, with alternative OMO errors comprising some $85 \%$ or so of the total errors made. Third category errors constitute about $15-20 \%$ of errors only, and common items a negligible proportion of the whole. This confirms the results of Experiment 1, that the main effect of Parkinson's disease is to increase the number of errors made by shifting the response set spasmodically during a trial, whichever rule the subject is currently using.

\section{Discussion}

As in Experiment 1, the main difficulty shown by Parkinsonian subjects in Experiment 2 was an inability to maintain one response set when two possible response modes had been suggested to them. Their difficulty is not in understanding the relationships involved, since their Parkinsonism did not severely affect the accuracy of initial classification, but only caused interference on later trials (where the clinical severity of the disease correlated with the degree of disruption). Only the much-improved scores of trials 9 and 10 in each experiment support the notion that subjects can apply the rules once they are made explicit, and that therefore it must be in their initial formulation that the Parkinsonian impairment lies. Maybe the immediately preceding emphasis on the rule to be used buttressed the subjects' set for these trials as, in the Weigl test, telling the subject how to change rules helps them to do so. ${ }^{24}$

Nor is the Parkinsonian deficit due to distractibility or perseveration, for patients did not perseverate on one rule only; they did not get diverted to a third rule; and they did not perseverate on other features of the material either. Rather the difficulty consists of occasional intrusions from the alternative set into whichever is currently being used. Parkinsonian patients seem less able to maintain a set against competing alternatives than normal elderly subjects, and less able to check their responses and inhibit errors before they are made. The effect is spasmodic and likely to occur at any time in the sequence, and shows little improvement despite practice over several trials on a number of sessions.

Our results on the control of set in the OMO test echo others on a variety of mental tasks, so this behavioural characteristic may be widespread in Parkinsonian cognition. Thus Boshes $e t a^{25}$ found that Parkinsonian patients do not show a normal kinaesthetic after-effect on a tactile sizediscrimination task, although their initial judgements are normal; that is, they fail to adapt their perceptual judgement with experience. A similar failure to adapt to prism vision was noted by Bossom in monkeys. ${ }^{41}$ Teuber $^{4249}$ attributes perceptual errors on the Aubert test (setting a rod to the visual vertical with the body tilted) to the Parkinsonian subjects' failure to pre-set their sensory systems to take body tilt into account (a loss of "motor-sensory set"). Similarly Bowen ${ }^{50}$ claims that deficits on the Weinstein body-scheme test of spatial orientation are based on an inability of Parkinsonian patients to shift their perceptual set so as to read the "body map" correctly. She also found a parallel difficulty in following route maps on the ground in these patients. ${ }^{21}$

Perhaps the most interesting reference to a disturbance of set in relation to our study is that of Talland. ${ }^{15}$ He found no intellectual deficits in his (largely untreated) patients, but reported that they showed a higher rate of spontaneous reversal of view on the Necker cube than controls. They were also less able to control the switching of the two possible perceptions voluntarily-they reduced them less when trying to maintain one view and increased them less when trying to alternate between the two. Subjectively, performing on the OMO test feels very much like staring at the Necker cube or other figure-ground displays which produce sporadic involuntary alternations of perception in all subjects. ${ }^{51}$ That Parkinsonian patients have less control over these reversals than normals on both tests suggests that they are suffering from a general loss of set in both perceptual (attention) and motor (planning) functions. Such effects would not hinder 
perception or movement directly, but might well contribute to a patient's clumsiness or inappropriateness of movement on tasks requiring complex perceptual-motor co-ordination, as for example in handling machinery or driving, where adaptation to a continuously changing environment is necessary.

Bowen ${ }^{4052}$ has also attributed low scores on the WMS battery to a failure to maintain or shift sets, which affects all memory modes. Some observations of ours (to be reported) agree with this analysis, noting occasional quirky errors which lower Parkinsonian memory scores without suggesting that they are suffering from typical amnesic impairments.

Rats $^{30}$ and cats $^{31}{ }^{53}$ with caudate lesions have also been found to have difficulty on alternation tasks which require a repeated shift of response between two manipulanda, (although the most usual symptom found is perseveration on one of them).

In many ways the behavioural changes found in our experiment resemble those described in humans and animals suffering frontal cortical lesions. Although most studies of the WCST in frontal lesions describe their results in terms of perseveration, ${ }^{34}{ }^{54}$ there is considerable discrepancy between different accounts. In the version of the test most similar to the OMO, Nelson ${ }^{47}$ characterises frontal function in part as "the inhibition of one mode of response in favour of another when this becomes appropriate", a description which fits closely both our results and Bowen's. ${ }^{27}$ Cohen $^{55}$ has described a frontal disturbance in Necker cube reversal, paralleling that of Talland in Parkinsonian subjects. Other features of frontal performance which we have also found in Parkinsonism include the tendency to fail on a task after reaching a criterion level ${ }^{54}$ (which we have found here and in other tasks such as recall memory) and failure to check wrong responses before emitting them..$^{334}$ Some subjects also showed a form of dissociation between verbal and manual competence,,$^{334}$ being able to describe the rule required while still applying it haphazardly.

A difficulty in swapping over between two rules of choice has also been noted in frontal monkeys in situations where the stimuli are the same but the rules guiding the required choice are alternated, ${ }^{35}{ }^{44}$ and here again their difficulty is not due to an inability to form or apply a rule as such, because the animals could discriminate easily using either of two rules, provided only one was required throughout a test session.

All this suggests that the Parkinsonian deficit on the OMO resembles a frontal effect, although it must be admitted that this remains only a plausible hypothesis at the moment, until the OMO is shown to produce similar deficits in frontal cortical patients and not in those suffering posterior lesions. But if this similarity is confirmed, it has two interesting implications: (a) firstly, that Parkinsonism is associated not with a general dementia, but rather with behavioural changes similar to those usually associated with anterior cortical dysfunction. It is arguable whether dementia may start in a similar fashion as here, and that in mild and moderate Parkinsonian cases we are seeing its initial stages. But it is equally arguable that the effect is more specific, and hence that Parkinsonian patients are not to be grouped with Alzheimer's disease. They may be better described in terms of subcortical dementia, limbic system dementia, or frontal disorder. Further studies of the cognitive capacity of these patients is required to distinguish between these possibilities. Certainly it seems unlikely that mild and moderate cases, at least, are demented. (b) secondly, the "flow-diagram" of basal ganglia connections has until recently indicated that these structures take their input from higher cortical levels of the CNS and send their output to the motor system (motor cortex and spinal cord). On this model, a malfunction in the basal ganglia should not affect the generation of ideas, but may interfere with the formulation of motor "programs" to execute them efficiently-as is often the case when subjects say "My hands won't do what I tell them to". The OMO results, however, suggest that Parkinsonism may also impair the organisation of actions at a higher level, that is, in the decision-making or planning level of skill, as has been found in a number of studies of voluntary movement. ${ }^{56-58}$ If so, it may be that the projection upwards from the basal ganglia to the higher levels of the central nervous system described recently ${ }^{2654}$ is functionally as important as the downward one, or that the frontal cortex and caudate system are so interconnected that they must be regarded as an integrated unit such that disruption at any point in the circuit impairs the function of the whole.

Seen in this light, the widespread effects of Parkinson's disease are not surprising, and, although restricted to certain characteristics of behaviour, will affect the whole of a patient's activities. Akinesia then becomes a general mental symptom, not just a restriction in movement of the limbs. It naturally follows that akinesia will be the major handicapping symptom in Parkinsonism, and that the degree of severity of the disease correlates with disruption of set in the OMO task. With a more accurate measure of bradykinesia the correlation with this kind of behavioural symptom should be closer.

This work was supported by grants from the Yorkshire Regional Health Authority and the Parkinson's Disease Society of Great Britain. We are 
indebted to Dr JMS Pearce for access to patients under his care, and to Dr Iris Pearce for providing the clinical assessments and Webster ratings on the Parkinsonian subjects. Hull Branch of the Parkinson's Disease Society kindly volunteered control subjects. We are also grateful to Mr P Oyston for help with statistical analysis, Mr A Marshall of Hull University Photographic and Copy Service for photographic work and Miss F Hunt for secretarial assistance.

\section{References}

' Pearce JMS. Mental changes in Parkinsonism. $\mathrm{Br}$ Med J 1974;i:449.

${ }^{2}$ Celesia GG, Wanamaker WM. Psychiatric disturbances in Parkinson's disease. Dis Nerv Sys 1972;33:577-83.

${ }^{3}$ Pirozzolo FJ, Hansch EC, Mortimer JA, Webster DD, Kuskowski MA. Dementia in Parkinson's disease: a neuropsychological analysis. Brain and Cognition 1982;1:71-83.

${ }^{4}$ Mayeux R. Depression and dementia in Parkinson's disease. In: Marsden CD, Fahn S, eds. Butterworths International Medical Reviews, Neurology 2: Movement Disorders. London: Butterworths Scientific 1982:75-95.

${ }^{5}$ Reitan RM, Boll TJ. Intellectual and cognitive function in Parkinson's disease. J Consult Clin Psychol 1971;37:364-9.

- Garron DC, Klawans HL, Narin F. Intellectual functioning of persons with idiopathic Parkinsonism. J Nerv Ment Dis 1972;154:445-52.

${ }^{7}$ Nyssen R, Wens M. Contribution à l'étude du déficit de l'intelligence chez les parkinsoniens encéphalitiques. Acta Neurol Belg 1948;48:287-307.

${ }^{8}$ Beardsley JV, Puletti F. Personality (MMPI) and cognitive (WAIS) changes after levodopa treatment. Arch Neurol 1971;25:145-50.

${ }^{9}$ Riklan M, Maskin M, Weissman D. Longer range L-Dopa behavioral arousal and psychological functions in the Parkinsonian. In: Siegfried J, ed. Parkinson's Disease: Rigidity, Akinesia, Behavior. Vol. 2. Bern: Hans Huber Publishers 1973:295-301.

${ }^{10}$ Guthrie TC, Dunbar HS, Weider A. L-Dopa: effects on highest integrative functions in Parkinsonism. Trans Am Neurol Assoc 1970;95:250-2.

" Rossor MN. Parkinson's disease and Alzheimer's disease as disorders of the isodendritic core. $\mathrm{Br} \mathrm{Med} J$ 1981;283: 1588-90.

${ }_{12}$ Pearce JMS. The extrapyramidal disorder of Alzheimer's disease. Eur Neurol 1974;12:94-103.

${ }^{13}$ Forno LS. Pathology of Parkinson's disease. In: Marsden CD, Fahn S, eds. Butterworths International Reviews, Neurology 2: Movement Disorders. London: Butterworths Scientific 1982:25-40.

${ }^{14}$ Gottfries CG, Adolfsson R, Aquilonius S-M, Carlsson A, Oreland L, Svennerholm L, Winblad B. Parkinsonism and dementia disorders of Alzheimer type: similarities and differences. In: Rinne UK, Klingler M, Stamm G, eds. Parkinson's Disease - Current Pro- gress, Problems and Management. Amsterdam: North Holland/Elsevier Biomedical Press 1980.

is Talland GA. Cognitive functions in Parkinson's disease. $J$ Nerv Ment Dis 1962;135:196-205.

${ }^{16}$ Asso D. W.A.I.S. scores in a group of Parkinson patients. Br J Psychiatry 1969;115:555-6.

${ }^{17}$ Loranger AW, Goodell H, McDowell FH, Lee JE, Sweet RD. Intellectual impairment in Parkinson's syndrome. Brain 1972;95:405-12.

${ }^{18}$ Horne DJdeL. Cognitive deficits in Parkinsonism. $\mathrm{Br}$ Med J 1973;ii:547-8.

${ }^{19}$ Matthews CG, Haaland KY. The effects of symptom duration on cognitive and motor performance in Parkinsonism. Neurology (Minneap) 1979;29:951-6.

${ }^{20}$ Riklan M, Diller L, Weiner H, Cooper IS. Psychological studies on effects of chemosurgery of the basal ganglia in Parkinsonism. I: Intellectual functioning. Arch Gen Psychiatry 1960;2:22-31.

${ }^{21}$ Bowen FP, Hoehn MM, Yahr MD. Parkinsonism: alterations in spatial orientation as determined by a route-walking test. Neuropsychologia 1972;10:35561.

22 Aubrun W. Réponses aux émotions-shocs chez les Parkinsoniens. Annee Psychol 1937;37:140-71.

${ }^{23}$ Elithorn A, Lunzer M, Weinman J. Cognitive deficits associated with chronic hepatic encephalopathy and their response to levodopa. J Neurol Neurosurg Psychiatry 1975;38:794-8.

${ }^{24}$ Barbeau A. Contributions of levodopa therapy to the neuropharmacology of akinesia. In: Siegfried J, ed. Parkinson's Disease: Rigidity, Akinesia, Behavior. Vol. 1. Bern: Hans Huber Publishers 1972.

${ }^{25}$ Boshes B, Arbit J, Dolkart M. Disorders of behavior and mentation resulting from the use of L-Dopa. In: Yahr MD, ed. Current Concepts in the Treatment of Parkinsonism. New York: Raven Press 1974.

${ }^{26}$ Lees AJ, Smith E. Cognitive deficits in the early stages of Parkinson's disease. Brain 1983;106:257-70.

${ }^{27}$ Bowen FP, Kamienny RS, Burns MM, Yahr MD. Parkinsonism: effects of levodopa treatment on concept formation. Neurology (Minneap) 1975;25:701-4.

${ }^{28}$ Rosvold HE, Mishkin M, Szwarcbart MK. Effects of subcortical lesions in monkeys on visualdiscrimination and single alternation performance. $J$ Comp Physiol Psychol 1958;51:437-44.

${ }^{29}$ Battig K, Rosvold HE, Mishkin M. Comparison of the effects of frontal and caudate lesions on discrimination learning in monkeys. J Comp Physiol Psychol 1962;55:458-63.

${ }^{30}$ Gross CG, Chorover SL, Cohen SM. Caudate, cortical, hippocampal and dorsal thalamic lesions in rats: alternation and Hebb-Williams maze performance. Neuropsychologia 1965;3:53-68.

${ }^{31}$ Buchwald NA, Hull CD, Levine MS, Villablanca J. The basal ganglia and the regulation of response and cognitive sets. In: Brazier MAB, ed. Growth and Development of the Brain. New York: Raven Press 1975.

32 Öberg RGE, Divac I. "Cognitive" functions of the neostriatum. In: Divac I, Öberg RGE, eds. The Neostriatum. London: Pergamon 1979.

${ }^{33}$ Luria AR. The Working Brain. London: Penguin 1973. 
${ }^{34}$ Milner B. Some effects of frontal lobotomy in man. In: Warren JM, Akert K, eds. The Frontal Granular Cortex and Behavior. New York: McGraw-Hill 1964.

${ }^{35}$ Settlage $\mathrm{P}$, Zable M, Harlow HF. Problem solution by monkeys following bilateral removal of the prefrontal areas. VI: Performance on tests requiring contradictions in reactions to similar and to identical stimuli. $J$ Exp Psychol 1948;38:50-65.

${ }^{36}$ Nauta WJH. Neural associations of the frontal cortex. Acta Neurobiol Exp 1972;32: 125-40.

${ }^{37}$ Rosvold HE. The frontal lobe system: corticalsubcortical interrelationships. Acta Neurobiol Exp 1972;32:439-60.

${ }^{38}$ Flowers KA. Frontal lobe signs as a component of Parkinsonism. Behav Brain Res 1982;5:100-1.

${ }^{39}$ Albert M. Subcortical Dementia. In: Katzman R, Terry RD, Bick KL, eds. Alzheimer's Disease, Senile Dementia and Related Disorders. New York: Raven Press 1978.

${ }^{40}$ Bowen FP. Behavior alterations in patients with basal ganglia lesions. In: Yahr MD, ed. The Basal Ganglia. Assoc. Res. Nerv. Ment. Dis. Publ. No. 55. New York: Raven Press.

${ }^{4} 1$ Bossom J. The effect of brain lesions on prism adaptation in the monkey. Psychonomic Sci 1965;2:45-6.

42 Teuber H-L. Complex functions of basal ganglia. In: Yahr MD, ed. The Basal Ganglia. Assoc. Res. Nerv. Ment. Dis. Publ. No. 55. New York: Raven Press 1976.

${ }^{43}$ Buffery AWH. Learning and memory in baboons with bilateral lesions of frontal or inferotemporal cortex. Nature 1967;214:1054-6.

${ }^{44}$ Iversen SD, Mishkin M. Perseverative interference in monkeys following selective lesions of the inferior prefrontal cortex. Exp Brain Res 1970;11:376-86.

${ }^{45}$ Lashley KS. The mechanism of vision: XV: Preliminary studies of the rat's capacity for detail vision. J Gen Psychol 1938;18:123-93.

${ }^{46}$ Berg EA. A simple objective technique for measuring flexibility in thinking. J Gen Psychol 1948;39:15-22.
${ }^{47}$ Nelson HE. A modified card sorting test sensitive to frontal lobe defects. Cortex 1976;12:313-24.

48 Webster DD. Critical analysis of the disability in Parkinson's disease. Mod Treatment 1968;5:257-82.

${ }^{49}$ Proctor F, Riklan M, Cooper IS, Teuber H-L. Judgement of visual and postural vertical by Parkinsonian patients. Neurology (Minneap) 1964;14:287-93.

${ }^{\text {so }}$ Bowen FP, Burns MM, Brady EM, Yahr MD. A note on alterations of personal orientation in Parkinsonism. Neuropsychologia 1976;14:425-9.

51 Vickers D. A cyclic decision model of perceptual alternation. Perception 1972;1:31-48.

s2 Bowen FP, Burns MM, Yahr MD. Alterations in memory processes subsequent to short- and long-term treatment with L-Dopa. In: Birkmayr W, Hornykiewicz O, eds. Advances in Parkinsonism. Basle: Editions Roche 1976.

${ }^{53}$ Olmstead CE, Villablanca JR, Marcus RJ, Avery DL. Effects of caudate nuclei of frontal cortex ablations in cats. IV: Bar pressing, maze learning and performance. Exp Neurol 1976;53:670-93.

${ }^{54}$ Drewe EA. The effect of type and area of brain lesion on Wisconsin Card Sorting performance. Cortex 1974; 10:159-70.

ss Cohen L. Perception of reversible figures by normal and brain-injured subjects. Arch Neurol Psychiat 1959;81:765-75.

${ }^{56}$ Flowers KA. Lack of prediction in the motor behaviour of Parkinsonism. Brain 1978;101:35-52.

${ }^{57}$ Stern Y, Mayeux R, Rosen J, Ilson J. Perceptual motor dysfunction in Parkinson's disease: a deficit in sequential and predictive voluntary movement. J Neurol Neurosurg Psychiatry 1983;46:145-51.

${ }^{58}$ Sharpe MH, Cermak SA, Sax DS. Motor planning in Parkinson patients. Neuropsychologia 1983;21:45562.

${ }^{59}$ Price KS, Farley I-J, Hornykiewicz O. Neurochemistry of Parkinson's disease: relation between striatal and limbic dopamine. Advances in Biochemical Psychopharmacology 1978;19:293-300. 